\title{
Environmental exposure to carcinogens in northwestern Cameroon
}

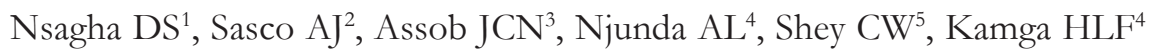

1. Department of Public Health \& Hygiene, Faculty of Health Sciences, University of Buea, Cameroon

2. Epidemiology Unit, International Agency for Research on Cancer, 150, Cours Albert Thomas, Lyon, France

3. Department of Biomedical Sciences, Faculty of Health Sciences, University of Buea, Cameroon

4. Department of Medical Laboratory Sciences, Faculty of Health Sciences, University of Buea, Cameroon

5. Institute of Infectious Disease and Molecular Medicine, Faculty of Health Sciences, University of Cape Town, South Africa

\begin{abstract}
Background: In developing countries, $6 \%$ of deaths are due to cancer but cancer prevention is not practiced. Humans can prevent themselves from a number of workplace and environmental carcinogens.

Objectives: To assess exposure to carcinogens, risky behaviours and associated preventive methods.

Methods: A structured questionnaire was used to collect information on carcinogen exposure in the workplace and environment through trained field staff from volunteers after gaining informed consent. Data was analysed using SPSS. Results: Participants were exposed to recognized carcinogens and environmental hazards. Thirty-five (83.3\%) [95\% CI: 72.0- 94.6] participants knew the carcinogen names they were exposed to. Common hygienic practices such as taking a bath and washing work dresses at the workplace, use of detergents to wash hands, and no smoking or eating at the workplace were poor. Twenty-nine (69.0\%) [95\% CI: 47.0 - 75.0] participants could smell the carcinogenic chemicals they use. Thirty (71.4\%) [95\% CI: 65.0 - 77.0] participants had been instructed in the use of protective equipment against carcinogens. Participants used preventive devices like hand gloves, laboratory coats, boots, face masks, goggles, ear plugs and respirators. Conclusions: Exposure to carcinogens is common necessitating case-control and cohort studies in this locality on cancer prevalence and incidence.
\end{abstract}

Keywords: Carcinogen, exposure, workplace, environment, risk assessment, prevention, Cameroon

African Health Sciences 2013; 13(3): 718 - 724 http:/ / dx.doi.org/10.4314/ahs.v13i3.28

\section{Introduction}

Occupational and environmental exposures to carcinogens are risk factors for cancer ${ }^{1-3}$ even though occupational exposure account for $8 \%$ of all human cancers ${ }^{4}$. Tobacco 5 , excessive alcohol ${ }^{6}$, excessive sunrays exposure ${ }^{7}$, radiation ${ }^{7}$, wood dust $^{8}$, dyes, tar, bitumen, benzene ${ }^{9}$, chloroform ${ }^{10}$, dietary fat ${ }^{11}$, cigarette smoking ${ }^{12}$, automobile diesel exhausts ${ }^{13}$, and locally brewed alcoholics ${ }^{14}$ are common workplace carcinogens. In developing countries, cancer treatments is emphasized more than cancer prevention but since one-third of cancers are preventable, knowledge of carcinogen predisposing factors will lead to more effective preventive approaches ${ }^{15}$.

\section{*Corresponding author: \\ Dickson Nsagha \\ Department of Public Health \& Hygiene Faculty of Health Sciences, University of Buea P.O.Box 63 Buea, Cameroon \\ Tel: (237) 77499429 \\ Email:dsnsagha@gmail.com \\ nsaghads@hotmail.com}

Many viral, bacterial, parasitic and fungi diseases including non-communicable diseases like diabetes, hypertension, cardiovascular diseases, etc, are common in north western Cameroon. A study by Nkegoum $^{16}$ revealed that the most common cancer in the general population in Cameroon was liver cancer but cervical cancer was the most common among women. Prostate and liver cancers are the most common among men accounting for the leading causes of death while breast cancer is the most common among women but cervix and uteri caners are the leading causes of death. Lung cancer has been reported from Cameroon ${ }^{17}$ but no association has been established between cigarette smoking and lung cancer or any identified carcinogens and other forms of cancer in the country. Owing to the high cancer cases reported from Yaounde ${ }^{18-21}$, another urban centre of Cameroon, it was necessary to carry out this survey on workplace and environmental carcinogen exposure, risk assessment and prevention in this locality.

The aim of this study was to identify carcinogens in Bamenda, how the population is

African Health Sciences Vol 13 Issue 3 September 2013 
exposed to them and the preventive methods used against these exposures.

\section{Methods}

\section{Study area}

The study took place in Bamenda, the North West Provincial (now Region) capital of Cameroon with a population of about 80,000 inhabitants. Bamenda has a short dry season from October to February and a long rainy season from March to September. It is located in the savannah. Common factories in Bamenda include: milk, soap, poultry, fishing, bakeries, printing, wood processing, rice hauling and two beer brewery depots. Pastoral farming consists of cattle and sheep rearing. Goat, pig, and chicken rearing are common and peasant farming is practiced by most inhabitants. The town has many mechanic's, panel beater's , iron bender's, automobile sprayer's, welder's, old vehicle spare part seller's workshops and hair dressing saloons. There are many carpentry workshops and beer parlours. Local liquor production like palm wine, raffia wine, and corn beer are common. The beer is made from maize (the maize is sucked in water for three days and allowed to ferment and ground to paste to manufacture the alcohol). There are three large markets: Nkwen, Commercial Avenue and Kololon.

\section{Participant selection techniques}

Forty-two people participated in the study from February 2000 to October 2002. Most study participants were farmers (local peasant farmers and plantation tea workers), factory workers (soap, poultry, fishing, bakeries, wood, rice and beer distributors), health workers (nurses, laboratory technicians, nursing assistants), artisans (mechanics, carpentry, bricklayers, small scale traders, hair saloon barbers and dressers), teachers and students of secondary and high school including allied health sciences students. All racial groups (Black Africans and Fulanis) in Bamenda were included in the study.

The participants' consent was sought and volunteers were recruited into the study. Subjects who could not read or write English were communicated to in Pidgin English. A survey of workplaces aimed at describing the carcinogenic exposure of the employed population was carried out using a structured questionnaire. The filling of the questionnaire was carried out after lengthy discussions of the objectives and advantages of the study to the respondents. The questionnaire contained demographic characteristics on age, sex, occupation; length of time the person has been on the job, current exposure, past exposure, and how the exposure occurred, what one was exposed to, the precise name of the carcinogen, risky predisposing carcinogen behaviours and carcinogen prevention. The data was analysed on SPSS at 95\% confidence interval. The data was not adjusted in each category of participants. We conducted a crude measure for this descriptive study.

\section{Results}

Thirty-four (81.0\%) men and 8(19.0\%) women were surveyed. The participant's whose ages ranged from 19-61 years; the mean was $28.3 \pm 10.8$; were farmers, health workers, factory staff, students, artisans and teachers. They held different or the same job(s) continuously from 1982-2002. The mean time on a job was 8 years.

Table 1 shows the carcinogenic and non-carcinogenic materials the respondents were exposed to. Thirtysix $(85.7 \%)$ respondents indicated that household members had been exposed to various types of metals, fibres, chemicals, fumes, radiation and biological agents in the past. Two (4.8\%) were exposed to vehicles smoke, $3(7.1 \%)$ to firewood kitchens smoke, $1(2.4 \%)$ to burnt dirt and $1(2.4 \%)$ to $\mathrm{x}$-ray radiations. Five $(11.9 \%)$ participants were aware that they are exposed to natural radioactive radiations, $20(4.8 \%)$ to metals at automobile mechanic garages, welder's shop, iron bender's shop and panel beater garages; $1(2.4 \%)$ to dyes, $4(9.5 \%)$ to hospital infections, $4(9.6 \%)$ to chemicals, $3(7.1 \%)$ to smoke, $1(2.4 \%)$ to fertilizer, $12(28.6 \%)$ to fumes, $6(7.2 \%)$ to chemicals in hair saloons, and $1(2.4 \%)$ to wood dust.

Thirty-five $(83.3 \%)$ participants knew the names of the carcinogens they were exposed to. Participants could not remember the names of most carcinogens except for names on the questionnaire. Common names mentioned included steel and iron$1(2.4 \%)$, calcium oxide-1 $(2.4 \%)$, detergent $-2(4.8 \%)$, hydrogen sulphide $-2(4.8 \%)$, disinfectant-3(7.1\%), izaal-1(2.4\%), tin-1(2.4\%), lead-1(2.4\%), carbon dioxide $-5(11.9 \%)$, gamaline- $1(2.4 \%)$, mercury oxide$1(2.4 \%)$, magnesium-1(2.4\%), insecticides-10(23.8\%), iron filings- $7(16.7 \%)$, acids- $3(7.1 \%)$, formaline$2(4.8 \%)$, hydrogen peroxide- $2(4.8 \%)$, hair dressing chemicals- $6(7.2 \%)$, carbide- $1(2.4 \%)$, iron-2 (4.8\%), paint-1 (2.4\%), ultra-violet sun rays-6(14.3\%), acetylene gas [3(7.1\%), firewood smoke [9(21.4\%)] and fumes $[3(7.1 \%)]$. 
Table 1: Exposure to carcinogens and environmental hazardous material by the study population

\begin{tabular}{lcc}
\hline Carcinogenic material & $*$ No (\%) & Ranking \\
\hline Coal tar & $35(83.3)$ & $1^{\text {st }}$ \\
Disease-causing microorganisms & $35(83.3)$ & $2^{\text {nd }}$ \\
Fibres & $34(81.0)$ & $3^{\text {td }}$ \\
Kitchen/vehicle/burnt dirt smoke & $33(78.6)$ & $4^{\text {th }}$ \\
Chemicals & $25(59.5)$ & $5^{\text {th }}$ \\
Fumes & $25(59.5)$ & $5^{\text {th }}$ \\
Radiations & $25(59.5)$ & $5^{\text {th }}$ \\
Metals & $21(50.0)$ & $6^{\text {th }}$ \\
Ultra-violet sun rays & $13(31.0)$ & $7^{\text {th }}$ \\
Cigarette smoking & $8(19.0)$ & $8^{\text {th }}$ \\
Various drugs & $4(9.5)$ & $9^{\text {th }}$ \\
Wood dust & $1(2.4)$ & $10^{\text {th }}$ \\
Non-carcinogenic environmental hazardous material & \\
Untarred road soil dust & $35(83.3)$ & $1^{\text {st }}$ \\
Farm soil dust & $34(81.0)$ & $2^{\text {nd }}$ \\
Black board chalk & $8(19.0)$ & $4^{\text {th }}$ \\
Loud noise & $32(76.2)$ & $3^{\text {td }}$ \\
Bad toilet odour & $2(4.8)$ & $5^{\text {th }}$ \\
Bad municipal waste odour & $2(4.8)$ & $5^{\text {th }}$ \\
Harmattan cold & $2(4.8)$ & $5^{\text {th }}$ \\
\hline
\end{tabular}

$*$ No $=$ Number

$1=$ 'Harmattan cold' is a form of very severe cold that is experienced in the morning and evening during the dry season.

Answers to five questions to assess the risk of exposure of participants to potential carcinogens are shown in tables 2 . Table 3 shows results on whether participants protect themselves from exposure to potential carcinogens. The proportion of the study sample that was instructed in the use of protective equipment against potential carcinogens was $71.4 \%$ (95.0\% CI: 57.0 - 85.0). The preventive devices

included use of hand gloves [23(54.5\%)], laboratory coats or protective garments [6(14.3\%)], boots [3(7.1\%)], face caps [(2.2.4\%)], face masks [6(14.3\%)], goggles $[1(2.4 \%)]$, ear plugs $[1(2.4 \%)]$, respirators [2(4.8\%)], and other protective clothing [8(19.0\%)]. Table 4 shows that more students [7(16.7\%)] and health workers $[6(14.3 \%)]$ than other professions indicated that they use protective clothing to prevent direct exposure to carcinogens on the skin.

Table 2: Assessment of risky behaviours among the study participants

\begin{tabular}{|c|c|c|c|}
\hline \multirow{3}{*}{ Assessment of risky behaviours } & \multicolumn{2}{|l|}{ Response } & \multirow{3}{*}{$\begin{array}{l}95 \% \\
\text { Confidence interval }\end{array}$} \\
\hline & Yes & No & \\
\hline & $*$ No $(\%)$ & No $(\%)$ & \\
\hline Carcinogenic material on your skin? & $17(40.5)$ & $25(59.5)$ & $53.0-67.0$ \\
\hline Carcinogenic material on your clothing? & $25(59.5)$ & $17(40.5)$ & $57.0-67.0$ \\
\hline Smoking at the workplace? & $21(50.0)$ & $21(50.0)$ & $35.0-65.0$ \\
\hline Eating at the workplace? & $26(61.9)$ & $16(38.1)$ & $53.0-77.0$ \\
\hline Washing work clothes at the work place? & $8(19.0)$ & $34(81.0)$ & $23.0-31.0$ \\
\hline
\end{tabular}

$*$ No $=$ Number 
Table 3: Practice of prevention of exposure to carcinogens by the study participants

\begin{tabular}{llll}
\hline $\begin{array}{l}\text { Practices of prevention of } \\
\text { exposure to carcinogens }\end{array}$ & \multicolumn{2}{c}{ Response } & $\begin{array}{c}\mathbf{9 5 \%} \\
\text { Confidence interval }\end{array}$ \\
\cline { 2 - 3 } & $\begin{array}{l}\text { Yes } \\
* \text { No }(\%)\end{array}$ & $\begin{array}{c}\text { No } \\
\text { No }(\%)\end{array}$ & \\
\hline Taking a bath at home after work? & $5(11.9)$ & $37(88.1)$ & $7.0-16.0$ \\
Smelling the chemical one works with? & $29(69.0)$ & $13(31.0)$ & $47.0-75.0$ \\
Using protective equipment? & $28(66.7)$ & $14(33.3)$ & $53.0-81.0$ \\
Advised to use protective equipment? & $34(81.0)$ & $8(19.0)$ & $62.0-93.0$ \\
Instructed in the use of protective equipment? & $30(71.4)$ & $12(28.6)$ & $65.0-77.0$ \\
Wash hands with solvents after work? & $35(88.3)$ & $7(16.7)$ & $72.0-93.0$ \\
\hline
\end{tabular}

$*$ No $=$ Number

Table 4: Risk assessment of exposure to carcinogens among different professions of the study population

\begin{tabular}{|c|c|c|c|c|c|c|}
\hline \multirow{5}{*}{$\begin{array}{l}\text { Profession of the } \\
\text { Respondents }\end{array}$} & \multicolumn{6}{|c|}{ Exposure assessment questions } \\
\hline & \multirow{2}{*}{\multicolumn{2}{|c|}{$\begin{array}{l}\text { Get the material } \\
\text { (potential carcinogens) } \\
\text { on your skin or clothing? }\end{array}$}} & \multirow{2}{*}{\multicolumn{2}{|c|}{$\begin{array}{l}\text { Smell the } \\
\text { carcinogenic chemical } \\
\text { you are working with? }\end{array}$}} & \multicolumn{2}{|c|}{$\begin{array}{c}\text { Have you been } \\
\text { instructed in the use of the }\end{array}$} \\
\hline & & & & & equip & ent? \\
\hline & Skin & Clothing & Yes & No & Yes & No \\
\hline & $* \mathrm{No}(\%)$ & $\mathrm{No}(\%)$ & $\mathrm{No}(\%)$ & No $(\%)$ & No $(\%)$ & No $(\%)$ \\
\hline Farming & $5(62.5)$ & $3(37.5)$ & $6(75.0)$ & $2(25.0)$ & $6(75.0)$ & $2(25.0)$ \\
\hline Factory staff & $2(66.7)$ & $1(33.3)$ & $3(100.0)$ & $0(0.0)$ & $3(100.0)$ & $0(0.0)$ \\
\hline Health worker & $4(40.0)$ & $6(60.0)$ & $8(80.0)$ & $2(20.0)$ & $10(100.0)$ & $0(0.0)$ \\
\hline Artisan & $2(28.6)$ & $5(71.4)$ & $3(42.9)$ & $4(57.1)$ & $5(71.4)$ & $2(28.6)$ \\
\hline Teaching & $2(40.0)$ & $3(60)$ & $1(20.0)$ & $4(80.0)$ & $1(20.0)$ & $4(80.0)$ \\
\hline Student & $2(22.2)$ & $7(77.8)$ & $8(88.9)$ & $1(11.1)$ & $5(55.6)$ & $4(44.4)$ \\
\hline Total & $17(40.5)$ & $25(59.5)$ & $9(69.0)$ & $13(31.0)$ & $30(71.4)$ & $12(28.6)$ \\
\hline
\end{tabular}

$* \mathrm{No}=$ Number

The proportion of the study sample that could perceive the odour of carcinogenic chemical materials they work with was $69.0 \%$ (95\% CI: 55.0-83.0). More students, health workers and farmers said they could perceive the odour of chemicals they work with. Thirty-four $(81.0 \%)$ respondents indicated that their work clothes are washed at home compared to $8(19.0 \%)$ who wash theirs at the work place. None of the participants took a bath at work except five. The proportion of the study sample that was instructed in the use of work equipment was $71.4 \%$ (95\% CI: 63.0-80.0). Table 5 shows that the ability of the respondents to smell the carcinogenic chemical material and instructions on the use of protective equipment were significant.

\section{Discussion}

The participants were exposed to many carcinogens which could lead to high cancer incidence. Cancer patterns are characterised by a combination of poverty-related diseases, chronic health conditions, urbanisation, industrialization and a westernised lifestyle $\mathrm{e}^{22}$. These burdens exert more pressure on the health services compared to developed countries. Because little recognition is given to the cancer magnitude and other lifestyle diseases in Cameroon; prevention of unhealthy lifestyles, early diagnosis and cost-effective management are low resulting in inadequate cancer prevention. The impact of lifestyle and the environment on health is a growing area of concern in public health. Cancer is common in Cameroon and potentially fatal ${ }^{18}$. This cancer exposure survey data could be used for the evaluation and protection of environmental health and risk allocation for population subgroups or activities. The study has generated information for case-control and cohort studies on cancer incidence.

The assessment of cancer exposure risky behaviours such as whether the subjects get the carcinogen on their skin, smoke or eat at the 
workplace and wash work clothes at home were poor. This may have to do with ignorance of cancercausing agents in the environment ${ }^{23}$. Majority of the participants had been instructed in the use of protective equipment against carcinogens. This is commendable but education of the general public on the use of protective clothing and preventive devices against carcinogens is necessary. The ability of smelling the carcinogenic material and the instructions on the use of protective equipment was high. These may not have originally been targeted at cancer prevention per se but for the general health of the workers. It could not be distinguished whether the participants were exposed to carcinogens voluntarily or involuntarily. Individuals are capable of voluntarily reducing exposure to substances in diet and cigarette smoke but cannot feasibly control their exposure to air, water and workplace pollution 24 .

The greatest carcinogenic exposures were wood dust, fibres, chemicals, hair saloon products, fumes, radiation, microorganisms, extreme ultraviolet rays, smoke, and various metals. The impacts of environmental and occupational carcinogens on cancer incidence in Cameroon look elusive because no cut-off values are used as standards. According to Kelsey and Wiencke ${ }^{25}$, "there is no appropriate threshold of evidence for accepting exposure to environmental and occupational carcinogens with risk factors of cancer". The public health impact is that many cancers may occur in the study area. Primary prevention will play an important role instead of waiting for the disease to occur.

All participants were exposed to many carcinogens, maybe, because of the increasing population that leads to pollution and exposure to carcinogens. There is industrialization and urbanization; smoking is on the increase and there is continuous adaptation of a western-type diet and lifestyle ${ }^{26}$. Infectious diseases are also highly prevalent in the study area ${ }^{27}$. These determinants can contribute to increase in cancer incidence. Locally brewed alcohol and beer are commonly consumed in the study area which can predispose the population to cancer ${ }^{6,13}$ highlighting the fact that cancer incidence may eventually increase in Bamenda. Since risk factors for cancer normally start at young age and track to adulthood ${ }^{28}$, preemptive prevention would be good.

Loud noise, vibrations, bad toilet-odours and accumulated waste are environmental hazards to be addressed by health authorities. Environmental health policymakers should set priorities towards keeping the town clean by carrying debris heaps packed along streets, cleaning drainages and controlling the dumping of debris into the streams that flow through the town.

Among the different professions, a high level of protection from occupational and environmental carcinogens was observed with subjects wearing protective clothing compared to those who allowed the carcinogenic material on their skin. Participants who could smell the materials were clustered around health workers which demonstrate the awareness of cancer as a serious public health problem among them. No significant relationship was established between exposure to carcinogens and profession of the participants in this study.

Studies revealed that charred food is highly carcinogenic including meat (associated fats), sugar, salt; spicy foods, smoked food and excessive alcohol $^{29}$. Cassava which is widely consumed in the study area contains cyanogenic glucosides, which are associated with neurological disease apart from being carcinogenic. Plant foods such as maize and cassava can be stored in many mouldy forms which contain mycotoxins and substances with carcinogenic potential. Most carcinogens have adverse health effects other than causing cancer. For example, apart from causing cancer, wood dust can cause skin irritation, sensitization, asthma, rhinitis and chronic obstructive lung disease ${ }^{30}$. Radiation can cause cancer as well as burns, premature ageing, nausea, weakness, hair loss, skin burns or diminished organ function ${ }^{31}$.

Data reliability was ensured through rigorous training of data collectors before and during data collection in debriefing evening meetings using presentations and other adult learning strategies such as questions and answer sessions, demonstrations and role plays. The data collection tools were pretested before data collection. Daily evening meetings were also held with data collectors to crosscheck filled forms and collectors sent back to the field to complete incomplete or poorly filled questionnaires; questionnaires were keyed into the compute using different codes by two data entry clerks to avoid errors. The data collector training manuals and questionnaires were checked module by module and piece by piece instead of checking the whole at the end. Range and consistency errors were also conducted on the filled forms.

It was very difficult getting information from the study population except after long explanations of the advantages and objectives of the study. Two hundred people were contacted but only 42 accepted 
to participate in the study. Even though, the small sample size prevents the generalization of the findings to a larger population, this descriptive observational study has generated hypotheses that can be used for analytical case-control and cohort studies. Many people were suspicious why they were targeted for the survey. Despite these limitations, the assessment thus provides a reasonable tool for subsequent epidemiological studies and follow-up.

\section{Conclusion}

Sensitization campaigns to increase awareness on health hazards of occupational and environmental exposures to carcinogens should be carried out in this environment. There is no evidence that cancer occurrence is consistently higher in this environment because of the high level of exposure to carcinogens but analytical case-control and cohort studies are warranted to ascertain the presence of cancer among the population.

\section{Acknowledgements}

Dr. Bulus Tanyigna and Dr. John Mawak, University of Jos, Nigeria are thanked for editing the manuscript. Mr. Alfred Tantoh and Mr. Mbunwe Nsagha administered the questionnaire. Mr. Bernard Ndi Nsagha funded this work and the views expressed in this paper are not his.

\section{References}

1. Reif J, Pearce N, Fraser J. Cancer risks in New Zealand farmers. International Journal of Epidemiology 1989; 18(4):768-774.

2. Dubrow R, Megman DH. Cancer and occupation in Massachusetes: a death certificate study. American Journal of Industrial Medicine 1984; 6(3): 207-230.

3. Williams RR, Stegens NL, Goldsmith JR. Associations of cancer sites and type with occupation and industry from the third national survey interview. Journal of the National Cancer Institute 1977; 59(4): 1147-1185.

4. Doll R, Peto R. The causes of cancer: quantitative estimates of avoidable risk of cancer in the United States today. Journal of the National Cancer Institute, 1981; 66(3): 1191-1308.

5. International Agency for Research on Cancer. Monograph on the evaluation of carcinogenic risks to humans. Tobacco smoking, 1986; ISBN 9283215389.
6. International Agency for Research on Cancer. Monograph on the evaluation of carcinogenic risks to humans. Alcohol drinking, 1988; ISBN 9283212444.

7. International Agency for Research on Cancer. Monograph on the evaluation of carcinogenic risks to humans. Solar and ultraviolet radiation, 1992; ISBN 92832 1255X.

8. International Agency for Research on Cancer. Monograph on the evaluation of carcinogenic risks to humans. Wood dust and formaldehyde, 1995; ISBN 9283212622.

9. International Agency for Research on Cancer. Monograph on the evaluation of carcinogenic risks to humans. Silica, some silicates, coal dust and para-aramid fibils, 1997; ISBN 928321267 3.

10. Crump KS, Guess HA. Drinking water and cancer: review of recent epidemiological findings and assessment of risks. Annual Review of Public Health, 1982; 3(1): 339-357.

11. Cohon L. Diet and cancer. Scientific America 1987; 257(5): 42-48.

12. Steenland K, Deddens J, Stayner L. Diesel exhaust and lung cancer in the trucking industry: Exposure response analysis and risk assessment. American Journal of Industrial Medicine 1998; 34(3): 220-228.

13. International Agency for Research on Cancer. Monograph on the evaluation of carcinogenic risks to humans. Cadmium, nickel, some epoxides, miscellaneous industrial chemicals and general considerations on volatile anaesthetics, 1976; 9283212118.

14. Barker DJP, Hall AJ. In: Practical Epidemiology, Fourth edition, Longman Group, UK Ltd, 1991; pp. 1-3.

15. Magrat I, Litvak J. Cancer in developing countries: opportunity and challenge. Journal of the National Cancer Institute 1993; 85(11): 862873.

16. Nkegoum B. Cancer Control in Cameroon. UICC World Cancer Congress 2006. Bridging the Gap: Transforming Knowledge into Action. July 8-12, 2006, Washington, DC, USA.

17. Bray F, Ren JS, Masuyer E, Ferlay J. Estimates of global cancer prevalence in 2008 for 27 sites in the adult population. Available at: http:// www.medinfographics.com/global-cancerstatistics/cameroon/common-cancers-and- 
leading-cancer-deaths-in-cameroon/ Accessed 16 June 2012.

18. Yomi J, Monkam G, Tagni D, Doh A. Management of cervical cancers in Yaoundé [French]. Medicin Tropicale, 1996; 56(2): 159-162.

19. Doh AS, Choundong VN. Double primary malignancies in patients with gynecological cancers. African Journal of Reproductive Health 1997; 1(2): 96-102.

20. Angwafo FF. Migration and prostate cancer: an international perspective. Journal of the National Medical Association 1998; 90(11Suppl): S720S723.

21. Mbakop A, Yomi J, Yankeum J, Nkegoum B, Mouelle SA. Cancer localization in men and women aged over 50 in Cameroon [In French]. Bulletin du Cancer, 1997; 84(12): 1119-1222.

22. Murray CJL, Lopez AD. The Global Burden of Disease: A comprehensive Assessment of Mortality and Disability from Diseases, Injuries and Risk factors in 1990 and projected to 2020.

Boston, Massachusetts: Harvard School of Public Health, 1996.

23. Main E. How to avoid common cancer-causing agents. Available at: http:// www.msnbc.msn.com/id/34509515/ns/ health-cancer/t/how-avoid-common-cancercausing-agents/. Accessed 12 August, 2011.

24. Perera F. Boffetta P. Perspectives on Comparing Risks of Environmental Carcinogens. Journal of the National cancer Institute 1988; 80 (16): 12821293.

25. Kelsey KT, Wiencke JK. Growing pains for the environmental genetics of breast cancer; observations on a study of the glutathione stransferase. Journal of the National Cancer Institute 1998; 90(7): 484-485.

26. Steyn K. Conceptual framework for chronic diseases of lifestyle in South Africa. Available at: http:/www.mrc.ac.za/chronic/cdlchapter1.pdf. Accessed 20 July, 2011.

27. Demographics of Cameroon. Available at: http:/ / en.wikipedia.org/wiki/ Demographics_of_Cameroon\#Major_ infectious_diseases. Accessed May 14, 2011.

28. Proctor MH, Moore LL, Singer MR, Hood MY, Nguyen US, Ellison RC. Risk profiles for non- communicable diseases in rural and urban school children in the Republic of Cameroon. Ethnography and Disease 1996; 6(3-4): 235-243. 